\title{
What Counts as Literacy in Health Literacy: Applying the Autonomous and Ideological Models of Literacy
}

\author{
Anne Marie Liebel-Health Communication Partners LLC
}

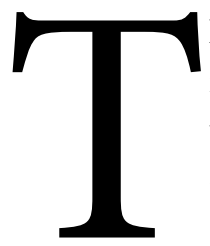

his essay is part of a five-year, cross-sector journey. I am an educator and consultant in health care. Prior to this, I was a literacy and education professor and classroom teacher. Brian Street was my professor at University of Pennsylvania's Graduate School of Education in the Language, Literacy and Education program.

Street's approaches and methods matter to my understandings of literacy-as well as to how I explore others' understandings of literacy. When I first started to work in the health sector, I was struck (as many others have been) by formal definitions of health literacy because they seemed to invite deficit views of patients (Liebel) and equate literacy with reading. Using some of the ethnographic tools and orientations I learned from Street, I began to understand health literacy as a field of study and also a health topic that many people care about, work on, and work with in various ways and in a range of contexts. In reading research and observing and communicating with people in the fields of medicine and public health, I learned that they know more (and care more) about literacy, composition, and education than is reflected in the dominant conceptions of health literacy.

In this essay, I show how health literacy definitions currently reflect an autonomous model of literacy and its drawbacks. I share some of what I have learned from reading, observation, and participation in the health literacy field that suggests health literacy in practice is more complex than definitions reflect or support. I explore the contributions that perspectives from New Literacy Studies (NLS) have made to the field of health literacy by summarizing health literacy writing that is grounded in the ideological model of literacy and utilizes NLS concepts. I then argue an ideological approach to health literacy can support positive health outcomes by increasing available empirical tools and data, and by providing clarity in correctly identifying factors that contribute to health outcomes.

\section{Current Definitions of Health Literacy}

The conceptualization of literacy in health literacy has implications for research, practice, and policy. There are many definitions of health literacy-nearly two dozen. Two representative examples come from the US Centers for Disease Control and Prevention (CDC) and the World Health Organization (WHO). The CDC website page "What is Health Literacy?" offers a definition of what they call "personal health literacy" (which they define separately from "organizational health literacy," a concept I take up later in this essay): "Personal health literacy is the degree to which individuals have the ability to find, understand, and use information and services to inform 
health-related decisions and actions for themselves and others" (Centers for Disease Control and Prevention). This definition, released in August 2020, has several similarities to the widely-cited definition from the Patient Protection and Affordable Care Act of 2010: health literacy is "the degree to which an individual has the capacity to obtain, communicate, process, and understand basic health information and services to make appropriate health decisions" (Centers for Disease Control and Prevention). Some version of this definition is cited at the start of many professional and popular articles about health literacy. The World Health Organization definition of health literacy is the basis for much national and international policy. Their website states that health literacy refers, broadly, to the ability of individuals to "gain access to, understand and use information in ways which promote and maintain good health" for themselves, their families and their communities (World Health Organization).

\section{Limitations of Dominant Conceptions of Health Literacy}

Several researchers have drawn attention to limitations in the dominant conception of health literacy reflected in most definitions, including that it encourages a deficit perspective on patients and clients (Hunter and Franken; McCormack et al.; Pleasant et al., Considerations), it has an overly limited scope (Peerson and Saunders), and it relies on tenuous or problematic relationships between literacy and health (Opel; Santos, Handley, Omark, and Schillinger.). I suggest these and other limitations relate to the model of literacy implicit in these definitions. Street encouraged those working in literacy "to see more clearly the underlying theoretical assumptions in writing on literacy, to recognize cleavages in the field, to expose hidden contradictions..." (Literacy in Theory and Practice 8). To enable this process, he offered two models of literacy: the autonomous and the ideological.

\section{The Autonomous Model of Literacy}

The autonomous model attempts to essentialize the technical components of language. It has been called the autonomous model for its implicit claim that literacy is a set of generic skills that, once learned, individuals can perform in any context. Focused primarily on individuals' reading skills, this view of literacy still underlies much formal literacy instruction for children and adults worldwide. Evident in such practices as vocabulary quizzes, reading comprehension tests, and texts written at a specific reading level, this is also the model beneath most large-scale assessments of literacy.

\section{Limitations and Consequences of the Autonomous Model in Health Literacy}

Those familiar with Street's work will see that the CDC and WHO definitions reflect the autonomous view of literacy. Perhaps most obvious is the focus on the individual. From Street's perspective, "The concept of the individual actor itself is a political construction, highly charged and central to much western political practice" (Literacy in Theory and Practice 33). In naming the individual as the unit of analysis, these definitions in effect locate health literacy as a "capacity" that exists within an individual. All three definitions above include a list of actions that the individual must perform. These signal an autonomous view because they place the focus on cognitive abilities, 
and they specify the performance of these specific skills as evidence that one's health literacy is adequate.

The use of the term "health information" in these and other definitions of health literacy also reflects an autonomous view of literacy. Health information refers to texts with which, owing to COVID-19, we are all now very familiar. These are texts written for the general public, by health professionals, on topics such as biological processes, disease states, procedures, and medications, as well as what might be called healthy living and disease prevention guidance. We might all be able to imagine examples from COVID-19 for every one of these categories! Yet health information texts may also include pamphlets or discharge instructions handed to patients in the medical context, or the labels on medication bottles.

Preferred or correct ways of reading and understanding health information texts are implied in health literacy definitions, again reflecting an autonomous view. The autonomous model includes "claims for the objectivity and neutrality" (Literacy in Theory and Practice 4) of the meanings of texts. Such claims, Street points out, "should not be taken at face value since they serve more often to privilege the users' own beliefs than as rigorous standards of 'truth"' (Literacy in Theory and Practice 4). That is to say, health information texts tend to take for granted the perspectives of the healthprofessional-authors, treating their intended meaning as objective, correct, and self-evident. Perhaps unintentionally, the dominant conception of health literacy "reduces role of reader to passive recipient rather than active negotiator of meaning" (Literacy in Theory and Practice 117). Furthermore, if people read or interpret information differently than health professionals expect them to, they may seem to have low levels of health literacy, a topic I return to later with examples from research.

Dominant conceptions of health literacy also tacitly assume a directional relationship between literacy and health. This is another trait of the autonomous model, which "assumes a single direction in which literacy development can be traced, and associates it with 'progress,' 'civilisation,' individual liberty and social mobility" (Literacy in Theory and Practice 2) and-in this case-better health outcomes. These definitions suggest a straightforward linear process of inputs toward the goal of better health. Improved health is certainly an important goal. There are many factors and inputs that could improve a person's health, but the place of literacy or health literacy in this is far from clear. However, these definitions suggest a clear process: a person with high health literacy finds the right health information, reads and interprets it in the correct way, includes it in their decision-making, acts as any reasonable, well-informed person should, and then ... there is health. Street shows the assumptions behind this kind of thinking:

Such a view starts from the premise of 'normality'-that there are certain attributes of a "developed" (modern) society, and that some nations and people are seen to lack these attributes. In literacy terms, many people are seen to lack the formal literacy required of them to engage in education, training and the formal economy; inputs in the form of training are needed. (Rogers and Street 40)

There are many problems inherent in such a view. One is the tacit assumption that in order to be healthy, one must have high levels of health literacy. People who score "low" on health literacy assessments therefore are somehow not being healthy, or not doing health properly (Liebel). 
The importance of so-called "low" levels of health literacy to many in the health sector cannot be overstated. The health literacy field has been dominated by research that identifies groups of people with "low" health literacy (Pleasant et. al, "Health Literacy"), and a person's lack of adequate health literacy is taken to have consequences or implications of a far-reaching kind. A person or group's "low" health literacy is sometimes implicated in their poor health outcomes. Statistics about "low" health literacy rates among specific social groups have also been suggested as contributing to the high cost of health care, as "low health literacy is seen to add significantly to a wide range of health care costs" (Hunter and Franken 25).

Literacy in this sense becomes a symbolic key to many of the society's gravest problems: issues of ethnic poverty and unemployment can be turned into questions about why individuals failed to learn literacy at school, or continue to refuse remedial attention as adults, thus diverting blame from institutions to individuals, from power structures to personal morality...All of these issues become focused within a single, overdetermined sign - that of literacy. (Street, Social Literacies 125)

Perhaps the most damaging aspect of the autonomous model is that it hides the assumptions that lead to such conclusions (see Street, "Literacy Inequalities").

Before I turn to the ideological model of literacy, I look beyond these definitions and contextualize health literacy with what I have seen in practice as an educator and consultant in the health sector. There is evidence of the autonomous view of literacy in health literacy practice and research, but there are also indications that health professionals understand more about literacy than is reflected in the current definitions.

\section{Health Literacy In Practice}

Taking an ethnographic approach to health literacy means observing and talking with people. I have had many conversations about health literacy with health professionals--not only researchers, but people who are directly dealing with patients or clients. Though this process has not taught me why the health literacy field has been built upon the autonomous model of literacy, I have come to see that current conceptions of health literacy are somewhat circumscribed by the accountability pressures of the healthcare market and larger political forces. Here I give a brief overview of the most common ways I have observed and heard about health literacy in practice, in both medical and public health contexts.

\section{Medical Contexts}

When a person seeks medical care at a doctor's office or hospital, they are asked a series of questions. The answers are meant to inform the diagnosis and/or the treatment. Some of these questions are referred to as screening questions. Such questions as "do you live alone," "do you smoke or have you ever smoked," are designed to help clinicians "screen" patients along various social, emotional, or cultural factors. The answers can inform the care plan the patient will be asked to follow. Health literacy became a focus for screening because clinicians were concerned about whether 
or not people would need assistance following a care plan. This is because care plans typically involve reading different complex texts, such as written instructions for managing an illness or injury, the label on a medication bottle, or the consent form for a procedure.

Health literacy tests can be useful when they are determining whether someone's level of a needed literacy skill matches that of the tasks required. This is where health literacy research meets practice: much of current health literacy research involves developing validated screening tools for different populations (Weiss). There are many health literacy screening tools that clinicians can use, and new ones are constantly being developed. Screening tools are necessarily short, as they are given during a medical encounter and typically are brief surveys or questionnaires. However, sometimes a patient's performance on a health literacy assessment can be tacitly interpreted by professionals as a comment on a person's educational level or supposed intelligence.

\section{Public Health Contexts}

Because of COVID-19, public health has certainly come to the forefront of global conversations about health. If medicine is primarily concerned with helping people with illness or disease, public health is primarily concerned with helping people lead healthy lives in general, often through health promotion and disease prevention. Health promotion and disease prevention involve educating the public, and informing local, state, and federal policy, on a wide range of social/cultural and environmental issues related to health. Literacy and health literacy come into this work most directly through the informational texts that public health professionals communicate. The composing of health-related communication is one of the primary responsibilities of many public health professionals. These health information texts might include materials for a community health worker to share with clients, public service posters hung around mass transit, or a state department of health's social media feed or website. We all have seen these and many other modalities in use by public health agencies around the world regarding COVID-19 and the coronavirus. Public health professionals' primary concern is composing and disseminating these materials so audiences can read them and understand the information being shared.

For many public health professionals, making a text comprehensible by its intended audience is a health equity issue; if a text is not understood, people are prevented from accessing the information within it. All people should be able to have equal access to the information in a text. Therefore, significant attention is given to the composition process. In the US, several federal agencies provide guidelines for how public health professionals can create materials with health literacy in mind. The guidelines tend to focus on textual features such as sentence length, text complexity, and word choice. They also provide guidance on font, layout, and use of graphics. Several guidelines include suggestions for digital formats as well as print-based texts.

Significant effort is made to tailor health information texts to their intended audiences whenever possible. Understanding the audience for a specific communication is therefore important. Public health professionals reference or collect different kinds of data about audience characteristics and demographics, sometimes including health literacy. Professionals sometimes conduct surveys or questionnaires, or reference large data sets such as the National Assessment of Adult Literacy 
(NAAL), to learn about audiences' health literacy. In 2003, the NAAL added three questions about health literacy (Pleasant, "Second Look"), and the data from this are widely cited. The so-called "readability" of health information is often mentioned. Measures such as "Lexile scores" are easy to calculate, and professionals can use them as evidence that efforts to tailor the text have been made. This is important, as health professionals can be responsible for a high volume of texts. The largely unchallenged reason for calculating the so-called "reading levels" of a text is to make sure it is at or below a certain grade or age level, a level arrived at by consulting the most recent data from largescale literacy assessments of the intended audience. There are many layers of interest here for literacy researchers working from the ideological model.

Two developments in public health intersect frequently with health literacy in my reading and observation. "Social determinants of health" (SDOH) is a public health concept concerned with different contextual factors that impact (and are impacted by) health in order to inform policy and practice (Mikkonen and Raphael). Additionally, place- and space- based approaches to education and research in public health have gained in popularity. These place-based movements challenge purely global orientations to understanding health and wellness. They resonate with Barton and Hamilton's (1998) work on what they call "local literacies," and Street's literacy education work in various global contexts, where he argues "against the 'mass' campaign favoured in many agency circles and in favour of rooting campaign work in local cultures and local definitions of 'need"' (Social Literacies 16).

Health literacy in practice is more complex than definitions would make it seem. The medical and public health professionals I have met understand that their work involves literacy, composition and education, in many modalities; sometimes at an interpersonal, local level and sometimes at a mass media, global level. The introduction of the term literacy into medicine and public health fields years ago was met with some optimism. Many people have embraced the term health literacy-even as practitioners and researchers are concerned with the adequacy of the public definitions of health literacy and continue to struggle with its meaning. The ideological model of literacy may be helpful here.

\section{The Ideological Model of Literacy}

Street's ideological model of literacy is one of the touchstones of NLS approaches. This model is called ideological because it asserts that "literacy can only be known to us in forms which already have political and ideological significance" (Literacy in Theory and Practice 8) and therefore cannot be meaningfully isolated from context. It stresses that every use of literacy is embedded in social contexts which give it meaning. This shifts the understanding of literacy from a universal, generic set of technical skills to a set of social, contextualized processes. Importantly, the ideological model "does not attempt to deny technical skill or the cognitive aspects of reading and writing, but rather understand them as they are encapsulated within cultural wholes and within structures of power. In that sense the ideological model subsumes rather than excludes the work undertaken within the autonomous model" (Social Literacies 161). 


\section{Ideological Approaches to Health Literacy}

Ideological approaches to health literacy have been forwarded for more than 20 years by multiple researchers, working mainly in adult education contexts (e.g., adult ESL programs, adult literacy programs, and literacy programs in Global South contexts). Street himself was involved for years in what might now be called health literacy work. He applied NLS theories of literacy and learning to program design, policy, measurement, and evaluation of many national and international adult education programs in the US, UK, South Africa, Ghana, and Nepal. Street observed and participated in teaching health topics alongside literacy, or in the use of health topics as the content for teaching literacy (see Rogers and Street; Street, Literacy and Development).

Some of Street's contemporaries and students have also applied NLS concepts in adult education contexts. I chose the authors in this section because they specifically apply ideological models of literacy to their health literacy work, illustrating multiple concepts that can enrich health literacy research and practice. In this section, "The overall argument is that a view of literacy as everyday communicative practices, necessarily embedded in the relationships and politics of everyday social life, offer us new orders of interest and ways of thinking about literacy and health" (Freebody and Freiberg 5). These "new orders of interest and ways of thinking" are possible because of the ideological model. Specifically, the ideological model makes adequate conceptual space for researchers, educators and practitioners to apply multiple tools to notice, document, and analyze "the contextual factors that explain people's behaviour or performance" (Papen 17) in health situations where literacy is involved. In this way might be generated a clearer sense of the relationships between literacy and health, including what contributes to positive or negative health outcomes-all of which is obscured by the autonomous model of literacy.

\section{Contributions and Benefits of Ideological Approaches to Health Literacy}

Unlike those operating under an autonomous model, researchers working from the ideological model of literacy explicitly state the theories of literacy in their work. I share two examples to ground the research in this section. Peter Freebody and Jill Freiburg see "literacy and health as sets of interrelated cultural practices, highly dependent on context, informed, and themselves informing our other sets of knowledge and assumptions" (5). Uta Papen and Sue Walters suggest that "[a]nother way of looking at health literacy — and literacy more generally_is to think of it as social practices: as activities which are always embedded in specific situations and contexts and whose actual shape and meaning can only be understood within these contexts" (11).

Collectively, the studies referenced here contribute an understanding of literacy in context. Existing health literacy research has struggled to connect language to its use in contexts beyond the clinical environment of hospitals, doctors offices, and health services. Studies working from an NLS perspective explicitly make context their central concern in understanding literacy. They regularly use ethnographic tools and methods to research literacy in specific social situations. Together, these writings allow us to see how health literacy is situated in multiple contexts, including the clinical context, the education context, the policy context, the technology context, the home/family contexts, and larger community/social group contexts. 


\section{Health Literacy in Use}

One of the weaknesses of literacy assessments-large-scale or small-scale-is that they test decontextualized, imagined, or hypothetical uses of literacy. Health literacy assessments are similarly limited. A major contribution of the ideological model is that researchers investigate actual uses of health literacy instead of hypothetical or potential uses. In Papen and Walters (2008), we learn about participants engaging in different ways with health information texts including leaflets, test results, forms, letters, medicine packaging and inserts, and signage in hospitals. People keep diaries and records and write down questions. In Santos, Handley, Omark, and Schillinger (2014), we learn about an adult ESL class where students discuss health information with classmates and consider how they might talk with their friends and family about what they are learning in class. One benefit of these concrete examples of health literacy in use is that they may help researchers see the range and variation in the ways different people engage with and make meaning from the same text-and that these ways and meanings are socially situated and locally significant.

\section{Health Literacy in Structures of Power}

In health literacy research, there has been increased attention over the last several years to people's social networks as important parts of their health literacy. Sometimes, power differences in social relationships are mentioned, but studies do not often situate health literacy within these power relationships. Studies which reflect the ideological model of literacy, on the other hand, do situate health literacy in a dynamic relationship with power structures. They draw attention to the influence of power on literacy and also to "the ways in which literate practices actually shape not only relationships but differences in something so apparently standard and routinized as a consultation with a doctor" (Freebody and Freiberg 5).

The connections between health literacy and the significant power difference in the physician/ patient relationship are addressed in three studies using the ideological model of literacy. Papen and Walters (2008) found that health literacy is embedded in social relationships, including "hierarchical" (28) ones, such as between patient and provider, which can disempower patients. Their study found that health literacy related to feelings of confidence for some of their ESOL students, specifically "the confidence to speak to health professionals, the confidence to ask questions or to take a leaflet back to a doctor with a request for clarification" (Papen and Walters 33). Santos, Handley, Omark, and Schillinger (2014) also acknowledge the effect of this power differential on adult ESL students. Importantly, they add that this effect may be incorrectly interpreted by the health professional as the patient having difficulty with literacy. As a result, the curriculum for their adult ESL class included role plays for students to practice conversations with a physician.

Health information texts are part of the institutional context of health literacy. In the ideological model, written texts (like oral texts) are situated within power relationships. The results from Hunter and Franken suggest that health information texts may have a complex relationship to patients' experiences in the clinical context. In an analysis of over one hundred health information documents about cardiovascular disease and diabetes, Hunter and Franken found "the discourse of patient responsibility for self-care" (35) permeated these texts. This discourse suggests a specific 
subject position that patients should adopt in order to be seen as participating appropriately in the institutional context. The language of the texts "typically assumed educated readers," and cultural or linguistic diversity was not a strong textual feature, normalizing the perspectives of the healthprofessional-authors, while communicating assumptions and expectations about the ideal reader/ patient as educated and White. Hunter and Franken's findings further suggest that patients who differed from this typical reader could have different experiences and engagement with the text.

Yet Hunter and Franken (2016) go further and join these findings with others from their study to suggest these texts may have the effect of doubly disadvantaging minoritized patients. Patients who were less likely to engage with these texts in the ways expected by their clinicians may appear to be less involved in following the care plan. This is problematic because, as the researchers found, "practitioners' views of the extent to which patients were motivated to comply with self-management regimes appeared to influence their dispositions toward patients" (38). Therefore, minoritized patients could be doubly disadvantaged. First, patients may not engage with or interpret the text in the way they were expected, potentially missing important information. An unexpected way of handling the text or understanding its contents could then make patients appear less "motivated to comply" and therefore negatively impact the disposition of the medical practitioner toward them and their future care.

The clinical relationship is not the only power structure around health literacy. Santos, Handley, Omark, and Schillinger (2014) situate health literacy in power relationships, including people's social groups. Their class activities included considering how students could talk about the potentially difficult topics of health risks, and being screened for health risk, with peers and family members.

Collectively, these authors give a sense of what ideological approaches to health literacy might involve, and what might be gained from them. In this way, practitioners and researchers who are not in public health or medicine have much to contribute current discussions about health literacy. While each study author offers suggestions for adult educators, their findings clearly hold implications beyond the education sector.

One implication regards conducting and interpreting research on health literacy and its relationships to health outcomes. If the goal is improved health, it would seem important to isolate variables that contribute to ill health. Current conceptions of health literacy, as I have pointed out, oversimplify literacy and its relationships to health. As the above studies show, there are many potential problems related to the enacting of literacy practices in the textually mediated, unequal power dynamics of the clinical context. This may lead health professionals to assume that a person or group's health problem is attributable to literacy-a kind of misdiagnosis that might negatively impact health outcomes. For example, if a clinician believes the source of a health problem is in a patient's literacy, they may refer a patient for literacy support, and miss the true source of the problem-along with the opportunity to give the proper treatment.

\section{Health Literacy in Medical and Public Health Fields}

Street warned that "the dominant discourse of putting people into two categories of 'literate' and 'illiterate' means that there is a danger that only illiterates tend to be studied, and that the lack 
of literacy becomes the focus" (Rogers and Street 19). Unfortunately, this has been the case in health literacy research. This may be one of the more serious limiting effects of the autonomous model of literacy assumed in current health literacy definitions. Much is lost when the focus is only on those who have so-called "low" health literacy, or in reading off the supposed ill-effects of "low" health literacy.

One group of people who is consistently excluded as subjects in health literacy research is health professionals. At this point, I turn to the newly released "organizational health literacy" definition from the CDC: "Organizational health literacy is the degree to which organizations equitably enable individuals to find, understand, and use information and services to inform health-related decisions and actions for themselves and others" (Centers for Disease Control and Prevention). Though this definition is new, it reflects a long-standing view that clinicians are considered part of the organizational side of the health literacy process, opposite the patients. Their role, as members of the health care system, is to "enable" or help the patient develop health literacy. But clinicians' own health literacy is rarely considered. I suggest medical and public health professionals have health literacy and engage in health literacy in their professional roles and in their everyday lives. It is true that as health professionals, they "face qualitatively different language and literacy tasks" (Freebody and Freiberg 5) than do patients or the public. Yet health professionals consistently engage in health activities-regarding other people's health as well as their own. The cognitive and social processes they go through in enacting their professional roles, as well as those times when they negotiate their own or their family's health, count as health literacy.

This is not a minor point. The ideological model of literacy invites us to examine assumptions about people, context, and literacy within any approach to literacy. This is especially important when it comes to health professionals. Current definitions of health literacy hide or normalize the health literacy practices of health professionals. With an ideological approach to health literacy, health professionals might reflect on their professional language use. They could question common practices, processes, phrases, and terminology for their underlying assumptions about patients, health, health care, and literacy. This kind of questioning may be particularly relevant to research about the role that health professionals play in contributing to health inequalities through "systematic though nondeliberate ways" (Hall et. al 12), some of which have been found to be related to their language use during the patient encounter; in other words, to clinicians' health literacy.

\section{Implications of an Ideological Approach to Health Literacy}

The autonomous and ideological models of literacy invite practitioners and researchers to question the construction of health literacy as a fixed standard against which people can be shown as in deficit. Research is needed into how literacy is used in the various meanings and activities of healthy living, and of what constitutes successful participation in the health care system, and processes developed to strengthen these activities for everyone-and not just those of "low" health literacy.

The global pandemic has sharpened attention to the ways health, safety, and wellness are talked 
about, written about, interpreted, and enacted, and to how these ways intersect with culture and power. There are few more consequential interactions and decisions in our lives than those regarding our health. Medical and public health professionals are not the only people who hold better health outcomes as a goal. Each of us wants a good life for ourselves and those close to us. An ideological approach toward health literacy opens up other possibilities for action toward the goal of better health, through conceptual and empirical tools and clarity regarding the factors that contribute to the outcomes we seek. 


\section{WORKS CITED}

Centers for Disease Control and Prevention. "What is Health Literacy?" Health Literacy. Centers for Disease Control and Prevention, 2019, https://www.cdc.gov/healthliteracy/learn/. Accessed 18 Sept. 2020.

Freebody, Peter, and Jill Freiberg. "Adult Literacy and Health. Reading and Writing as Keeping-Well Practices." Research into Practice Series No. 5. National Languages and Literacy Inst. Australia, 1997, https://files.eric.ed.gov/fulltext/ED430088.pdf. Accessed 28 Feb. 2017.

Hall, William J., Mimi V. Chapman, Kent M. Lee, Yesenia M. Merino, Tainayah W. Thomas, B. Keith Payne, Eugenia Engm, Steven H. Day, and Tamera Coy. "Implicit Racial/Ethnic Bias among Health Care Professionals and Its Influence on Health Care Outcomes: A Systematic Review." American Journal of Public Health, vol. 105, no. 12, 2015, pp. e60-76, doi.org/10.2105/ AJPH.2015.302903. Accessed 11 Feb. 2017.

Hunter, Judy, and Margaret Franken. "Health Literacy as a Complex Practice." Literacy \& Numeracy Studies, vol. 20, no. 1, 2012, pp. 25-44, doi.org/10.5130/lns.v20i1.2618. Accessed 6 Dec. 2016.

Liebel, Anne Marie. "Applying Critical Theory to Disrupt Deficit Perspectives in Patient Communication and Health Literacy: '10 Minutes to Better Patient Communication' Podcast Series." Journal of Consumer Health on the Internet, vol. 24, no. 4, 2020, pp. 416-29, doi:10.1080 /15398285.2020.1831354.

McCormack, Lauren A., Colleen M. McBride, and Michael K. Paasche-Orlow. "Shifting Away from a Deficit Model of Health Literacy." Journal of Health Communication: International Perspectives, vol 21, sup. 2, 2016, pp. 4-5, doi.org/10.1080/10810730.2016.1212131. Accessed 11 Oct. 2016.

Mikkonen, Juha, and Dennis Raphael. "Social Determinants of Health: The Canadian Facts."

Toronto: York University School of Health Policy and Management, 2010, https://

thecanadianfacts.org/The_Canadian_Facts.pdf. Accessed 13 Apr. 2020.

Opel, Dawn S. "Challenging the Rhetorical Conception of Health Literacy: Aging,

Interdependence, and Networked Caregiving." Composing a Further Life, special issue of Literacy in Communication Studies, vol. 6, no. 2, 2018, pp. 136-50. licsjournal.org/OJS/index. php/LiCS/article/view/198. Accessed 1 Oct. 2019.

Papen, Uta. "Understanding Literacy and Health: Literature Review." National Research and Development Centre for Adult Literacy and Numeracy. Institute of Education, University of London, 2008, https://eprints.lancs.ac.uk/id/eprint/1212/. Accessed 6 Dec. 2016.

Papen, Uta, and Sue Walters. Literacy, Learning and Health. National Research and Development

Centre for Adult Literacy and Numeracy, Institute of Education, University of London, 2008, www.nrdc.org.uk/?p=278. Accessed 6 Dec. 2016.

Peerson, Anita, and Margo Saunders. "Health Literacy Revisited: What Do We Mean and

Why Does It Matter?” Health Promotion International, vol. 24, no. 3, 2009, pp. 285-96, https://10.1093/heapro/dap014. Accessed 24 June 2015.

Pleasant, Andrew. "A Second Look at the Health Literacy of American Adults and the National 
Assessment of Adult Literacy." Focus on Basics, 9B, pp. 46-52.

Pleasant, Andrew, Rima E. Rudd, Catina O’Leary, Michael K. Paasche-Orlow, Marin P. Allen, Wilma Alvarado-Little, Laurie Myers, Kim Parson, and Stacey Rosen. Considerations for A New Definition of Health Literacy. Discussion Paper, National Academy of Medicine, 2016, https://nam.edu/considerations-for-a-new-definition-of-health-literacy. Accessed 23 Apr. 2016.

Pleasant, Andrew, Jennifer Cabe, Kavita Patel, Jennifer Cosenza, and Richard Carmona. "Health Literacy Research and Practice: A Needed Paradigm Shift." Health Communication, vol. 30, 2012, pp. 1176-1180, doi.org/10.1080/10410236.2015.1037426. Accessed 28 Feb. 2017.

Rogers, Allan, and Brian Street. Adult Literacy and Development: Stories from the Field. NIACE, 2012.

Santos, Maricel G., Margaret A. Handley, Karin Omark, and Dean Schillinger. "ESL Participation as a Mechanism for Advancing Health Literacy in Immigrant Communities." Journal of Health Communication, vol. 19, no. 2, 2014, pp. 89-105, https://10.1080/10810730.2014.934935. Accessed 29 Sept. 2016.

Street, Brian. "Introduction: New Literacy Studies and Literacies across Educational Contexts." Literacies Across Educational Contexts: Mediating Learning and Teaching, edited by Brian Street, Caslon, 2005, pp. 1-21.

---. Literacy and Development: Ethnographic Perspectives. Routledge, 1988.

---. Literacy in Theory and Practice. Cambridge UP, 1984.

---. "Preface." The Social Uses of Literacy: Theory and Practice in Contemporary South Africa, edited by Mastin Prinsloo and Mignonne Breie, John Benjamins Publishing, 2013, pp. 1-9.

---. Social Literacies: Critical Approaches to Literacy Development, Ethnography and Education. Longman, 1995.

Street, Brian V. "Literacy Inequalities in Theory and Practice: The Power to Name and Define." International Journal of Educational Development, vol. 31, no. 6, 2011, pp. 580-86, https:// doi:10.1016/j.ijedudev.2010.09.005. Accessed 22 Jan. 2016.

Street, Brian, and Adam Lefstein. Literacy: An Advanced Resource Book. Routledge, 2007.

Weiss, Barry D. "Health Literacy Research: Isn't There Something Better We Could Be Doing?” Health Communication, vol. 30, no. 12, 2015, pp. 1173-175, doi.org/10.1080/10410236 .2015.1037421. Accessed 11 Oct. 2016.

World Health Organization. Health 2020: Education and Health Through the Life-course. World Health Organization: Copenhagen, 2015, https://www.euro.who.int/_data/assets/ pdf_file/0007/324619/Health-2020-Education-and-health-through-the-life-course-en.pdf. Accessed 25 July 2017. 